\title{
Primary Carnitine Deficiency
}

National Cancer Institute

\section{Source}

National Cancer Institute. Primary Carnitine Deficiency. NCI Thesaurus. Code C98864.

An autosomal recessive inherited disorder caused by mutations in the SLC22A5 gene. It is characterized by the presence of a defective protein called OCTN2 which is involved in the transportation of carnitine into the cells. This abnormality results in reduced energy production and accumulation of fatty acids in the tissues. Clinical manifestations of confusion, muscle weakness, hypoglycemia, encephalopathy and cardiomyopathy may be exacerbated during fasting. 